\title{
Work Assistive Mobile Robot for the Disabled in a Real Work Environment
}

\author{
Hyun Seok Hong, Jung Won Kang and Myung Jin Chung \\ KAIST \\ Republic of Korea
}

\section{Introduction}

Previous works related to welfare service robotics have mainly focused on assisting the disabled in their daily life. Robot systems such as the Intelligent Bed-Robot System (Kim et al. 2002) and Care Robot System (Yoo, 2003a) are designed to help the disabled in performing daily activities in specialized indoor environments. Human-machine interfaces such as Eye Gaze Estimation System (Yoo, 2003b) have been developed to facilitate easy control of the robot system. FRIEND (Martens, 2001) and KARES II (Bien, 2003) are wheelchair-based rehabilitation robotic systems equipped with a robot arm and are designed to help the disabled manipulate small objects such as food, drink, books, etc.

It is important that human beings have the opportunity to feel self-worth and happiness by living productive lives through their own vocation. Therefore, the development of a vocational robotic system has important implications with respect to welfare. Although some vocational assistive robots have been developed, they are limited to office environments. The robot RAID (Eftring, 1993), which was developed at the Rehabilitation Engineering Research Center in Sweden, assists in removing books from a bookshelf, ¿ิ bringing documents, and serving drinks in a office environment. The robot known as ¿. WALKY (Neveryd, 1994) can avoid obstacles while it maneuvers to deliver objects in a

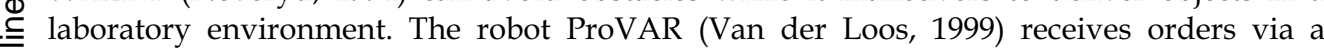
speech recognition system and helps to process office tasks such as serving drinks and delivering documents, diskettes, video tapes, etc. In addition, the current status of the robot $\stackrel{\Phi}{ \pm}$ is displayed through a monitor.

Due to regional differences in industrial structures, the types of tasks that the disabled can perform differ from country to country. As a result, robots assisting the disabled in a real () manufacturing environment can be more useful than robots providing assistance in office $\underset{\mathbb{N}}{\mathbb{N}}$ environments in some countries.

$\frac{0}{\pi}$ However, there has been relatively little research reported on the development of vocational $\vec{\pi}$ robotic systems in real manufacturing environments. The objective of the present work is to of develop mobile robot systems that assist the disabled to work in real manufacturing \& factories. Specifically, the assistive robot is targeted for the disabled in Korea, where the O authors dwell. In this research, to clearly determine the objectives of developing assistive mobile robots, a mission statement is addressed based on statistical data. Furthermore, the Ф target manufacturing environment is surveyed to specify the dimensions and working algorithm of the work assistive mobile robot. Two work assistive mobile robots are 
proposed and developed according to slightly different function definitions. User trials are performed for the two work assistive mobile systems. The robot systems are expected to provide practical assistance to disabled workers and help satisfy their desires and fulfill their capabilities so that they can become productive members of society. We expect that this will result in an increase in the working population of the disabled.

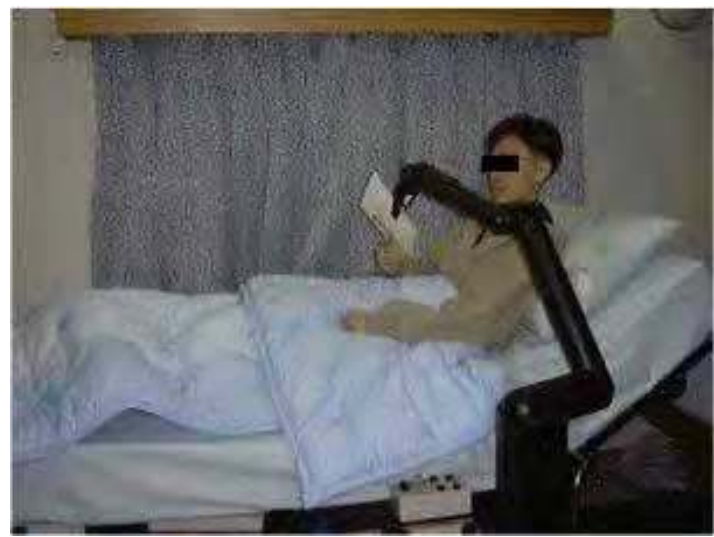

(a)

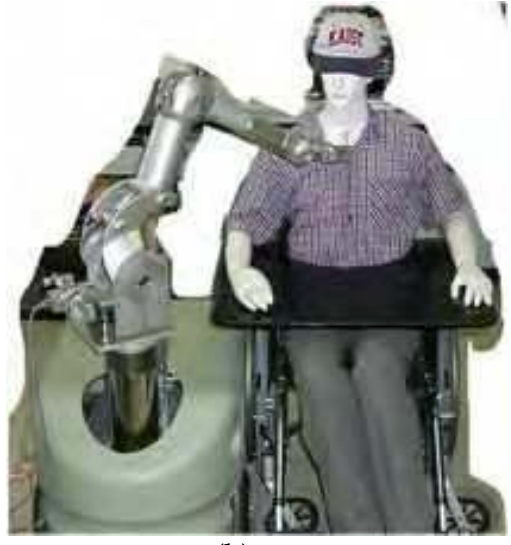

(b)

Fig. 1. Examples of robots for daily activities of the disabled; (a) Intelligent bed-robot system, (b) KARES II.

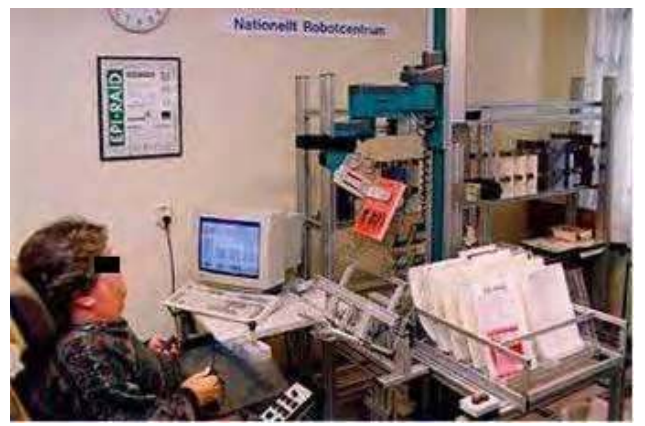

(a)

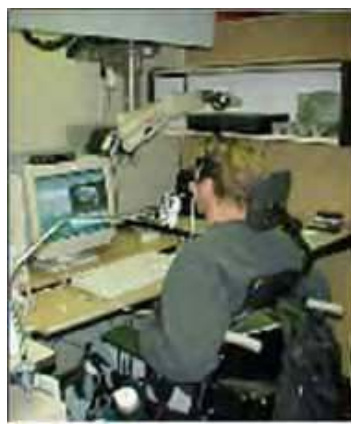

(b)

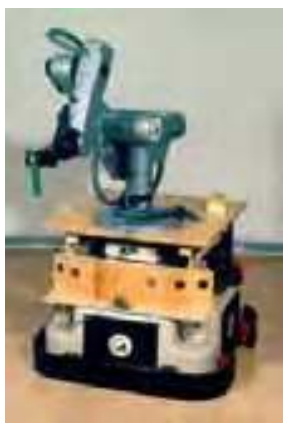

(c)

Fig. 2. Examples of robots for desktop vocational activities of the disabled; (a) RAID, (b) ProVAR, (c) WALKY.

\section{Derivation of Mission Statements}

Our objective in developing the present robot systems is to assist the disabled as much as possible in real employment situations. For determining our specific mission, we surveyed an abundance of data pertaining to people with disabilities in real employment situations. We categorized the survey results into three criteria, 'A. to assist the disabled as much as possible,' 'B. to consider the real situation of employment for the disabled and ' $\mathrm{C}$. to provide assistance for the most necessary tasks for the disabled in the work space'. 


\subsection{Survey based on Criterion A}

In order to assist the disabled as much as possible, we investigated disability types and the type of work presently being performed in Korea by workers with disabilities. To this end, we surveyed data ${ }^{1}$ on the disabled in Korea. Among people with disabilities, $55.1 \%$ suffer from limb impairment, $8.7 \%$ cerebral paralysis, 10.5\% visual disorder, $8.8 \%$ hearing disorder, and $0.8 \%$ speech disorder. On the other hand, there were relatively few people with internal organ impediments or cognitive disabilities.

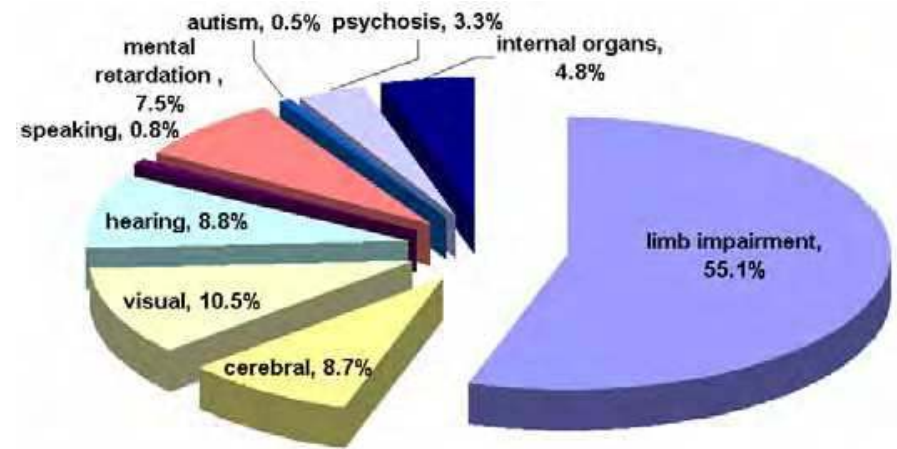

Fig. 3 Distribution of the disabled

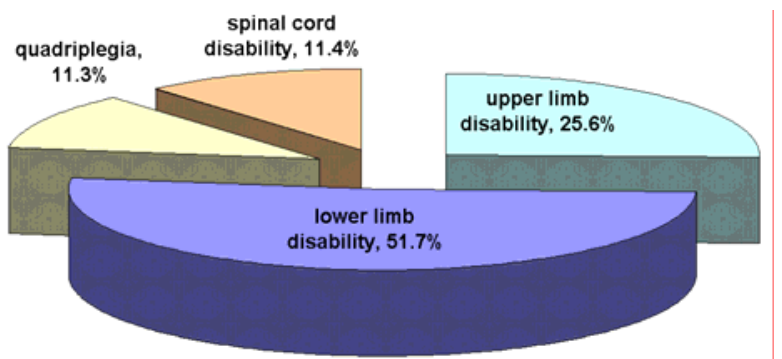

Fig. 4 Distribution of limb impairment and cerebral paralysis

\begin{tabular}{|c|c|c|}
\hline Types of disorder & Large workshop & Small workshop \\
\hline Limb impairment & $82.0 \%$ & $81.0 \%$ \\
\hline Cerebral paralysis & $0.2 \%$ & $0.2 \%$ \\
\hline Visual disorder & $4.4 \%$ & $3.1 \%$ \\
\hline Hearing disorder & $9.8 \%$ & $6.2 \%$ \\
\hline Speech disorder & $1.2 \%$ & $1.1 \%$ \\
\hline Other & $2.4 \%$ & $8.4 \%$ \\
\hline
\end{tabular}

Table 1. Distribution of actual employment for the disabled. Companies with more than 300 employees are classified as a large workshop.

${ }^{1}$ Statistical data from reports (written in Korean): "The present condition of registered disable people," published by the Korea Ministry of Health and Welfare, Sep. 2004, "Research on the actual conditions of the disabled in 2000," published by the Korea Institute for Health and Social Affairs, 2000, "Research on the actual conditions of disabled workers in 2000," published by the Korea Employment Promotion Agency for the Disabled, 2000. 
Fig. 3 shows the distribution of the disabled, and Fig. 4 describes the disability distribution of people who suffer from limb impairment or cerebral paralysis. From the distributions, it is noted that the percentage of disabled having leg impediments is large. Table 1 shows that most people with disabilities who have entered the workforce have limb impairment regardless of the scale of the workshop. Therefore, it is desirable to develop a robot system that assists workers who suffer from limb impairment.

\subsection{Survey based on Criterion B}

In order to assess the real employment situation of the disabled, we visited vocational education facilities $^{2}$ and companies ${ }^{3}$ that hire disabled workers. As shown in Fig. 5, our survey results show that the physically disabled tend to prefer computer-oriented jobs, as there are numerous occupations in this field and these jobs require little spatial movement. According to the results, they are also interested in mechanical jobs, primarily because there is huge industrial demand for labor and the other is that they can gain expertise in performing these jobs.

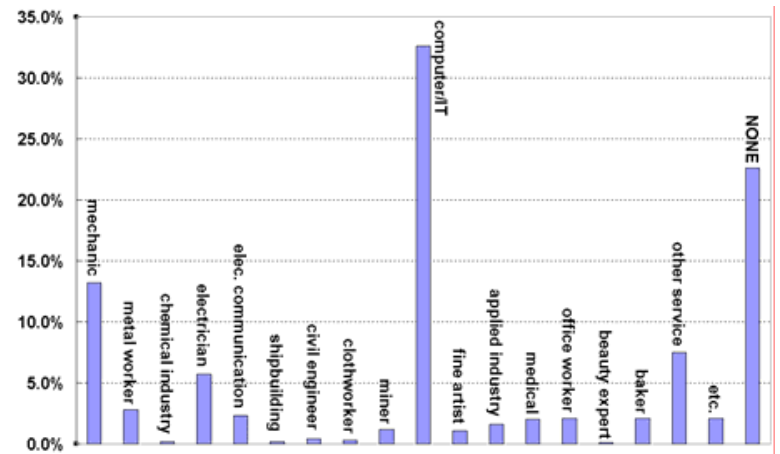

Fig. 5. Vocational fields in which the disabled desire training.

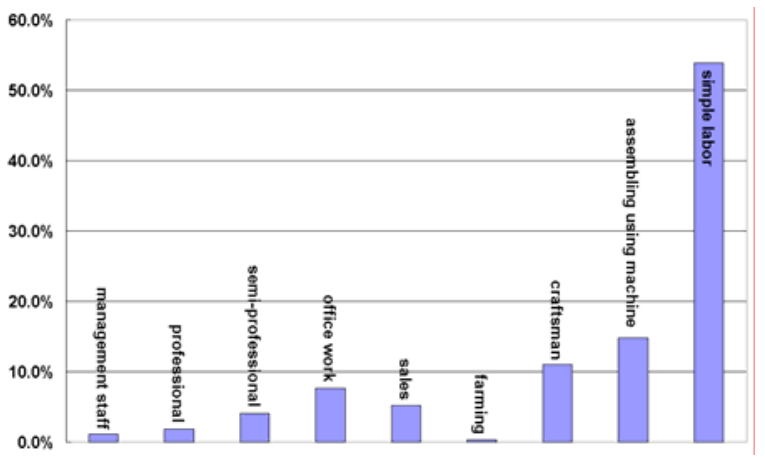

Fig. 6. Vocational fields for which the employers seek workers; 'simple labor' and 'assembling using a machine' include assembling and classifying circuit parts, moving boxes, packing, delivering, and cleaning up.

${ }^{2}$ Bundang branch of the Korea Employment Promotion Agency for the disabled and vocational schools in Daejeon and Ilsan.

${ }^{3}$ Eleven factories including Mugunghwa Electronics and Immanuel Electronics, which mainly make electronic products, and Boram-Dongsan, which mainly assembles mechanical parts. 
However, vocational fields 4 for which employers wish to hire disabled workers mainly involve simple labor, as shown in Fig. 6. According to these investigations, there are huge gaps between occupations that people with disabilities want and occupations that companies need to fill. As a result, although many social organizations provide vocational education to the disabled, due to the actual employment situation the disabled mainly perform simple labor. Therefore, it is desirable to develop an assistive robot system that can help the disabled work in performing physical and simple labor such as assembling and classifying circuit parts, moving boxes, and packing and delivering goods.

\subsection{Survey based on Criterion C}

According to the survey results shown in Table 2, disabled laborers experience difficulties when they should carry heavy materials.

\begin{tabular}{|c|c|c|}
\hline Situations & Large workshop & Small workshop \\
\hline Transferring goods & $55.4 \%$ & $33.8 \%$ \\
\hline Moving around the workshop & $14.5 \%$ & $31.5 \%$ \\
\hline Operating machines & $27.9 \%$ & $20.0 \%$ \\
\hline $\begin{array}{c}\text { Difficulty to understand } \\
\text { instructions }\end{array}$ & $24.4 \%$ & $22.3 \%$ \\
\hline Operating speed & $20.0 \%$ & $31.5 \%$ \\
\hline
\end{tabular}

Table 2. Situations where a disabled worker requires help. Duplicated answers are permitted. Companies with more than 300 employees are classified as a large workshop.

Survey results also show that those who have upper limb impediments desire a robot system that can help perform movements normally performed by the arms (fixing, loading, fine motion, etc). Those with leg impediments meanwhile require a system to substitute the functions of the leg (movement, loading, etc) and those who have both impediments would like a system that would provide assistance when they should carry heavy materials. Target objects for transferring goods are divided into heavy and light objects 5 . In the case of fine motion tasks, the assistive robot system cooperates with the human and supports roller inserting and PCB inspection tasks. Therefore, it is necessary to design a work assistive robot that can transfer goods, perform dexterous tasks, and move around freely.

From the above survey results, our mission has been determined. The following is our mission statement: to develop a work assistive mobile robot to help the disabled who have lower limb(s) or upper limb disabilities, or lower limb(s) and upper limb disabilities obtain employment in manufacturing factories involving the performance of simple physical labor.

\section{Work Space Environment of Real Manufacturing Factories}

\subsection{Work Space Environment of Real Manufacturing Factories}

As described earlier, our work assistive robot helps the disabled person to work in a real manufacturing factory. Before designing this assistive robot, the environments of real

${ }^{4}$ Statistical data from the report (written in Korean): "Classified statistics on the disabled in the first quarter of 2002," published by the Korea Employment Promotion Agency for the Disabled, 2002.

${ }^{5}$ Boxes used in a real factory are investigated and classified into two groups: heavy boxes (maximum size: $65 \times 35 \times 40 \mathrm{~cm}$, shape: box, maximum weight: $30 \mathrm{~kg}$ ), and light boxes (maximum size: $30 \times 25 \times 10 \mathrm{~cm}$, shape: box or bag, maximum weight: $3 \mathrm{~kg}$ ). 
manufacturing factories should be known. We surveyed several manufacturing factories that employ workers with disabilities. Through the survey, we defined the general environment to help the disabled. Manufacturing factory environment survey results are described in Fig. $7 \sim$ Fig. 10.

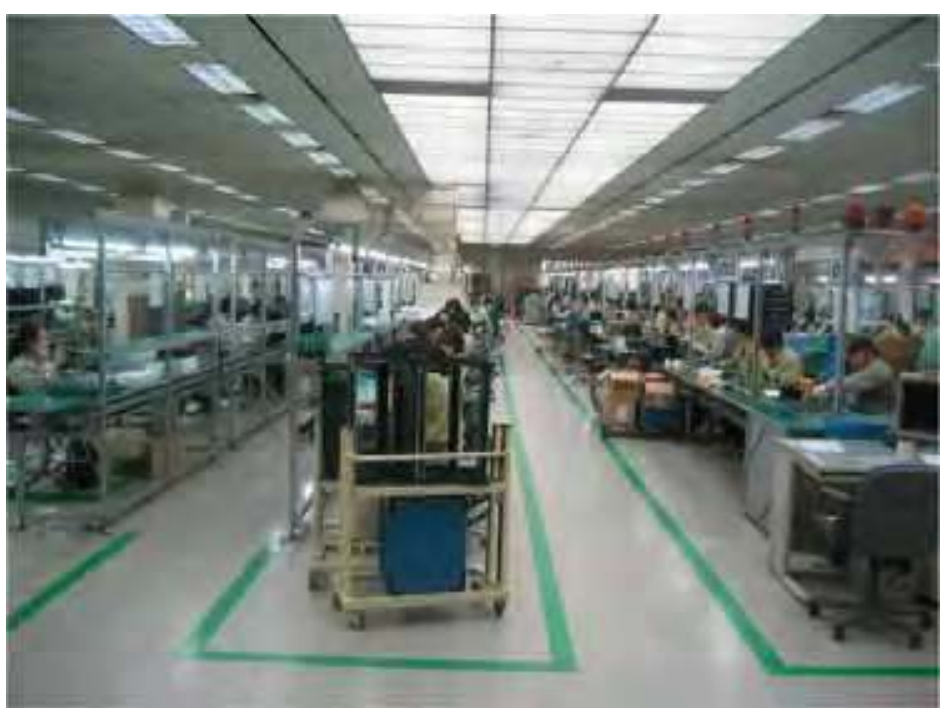

Fig. 7. Whole view of general environment of manufacturing factory. Safety lines are painted around work tables.

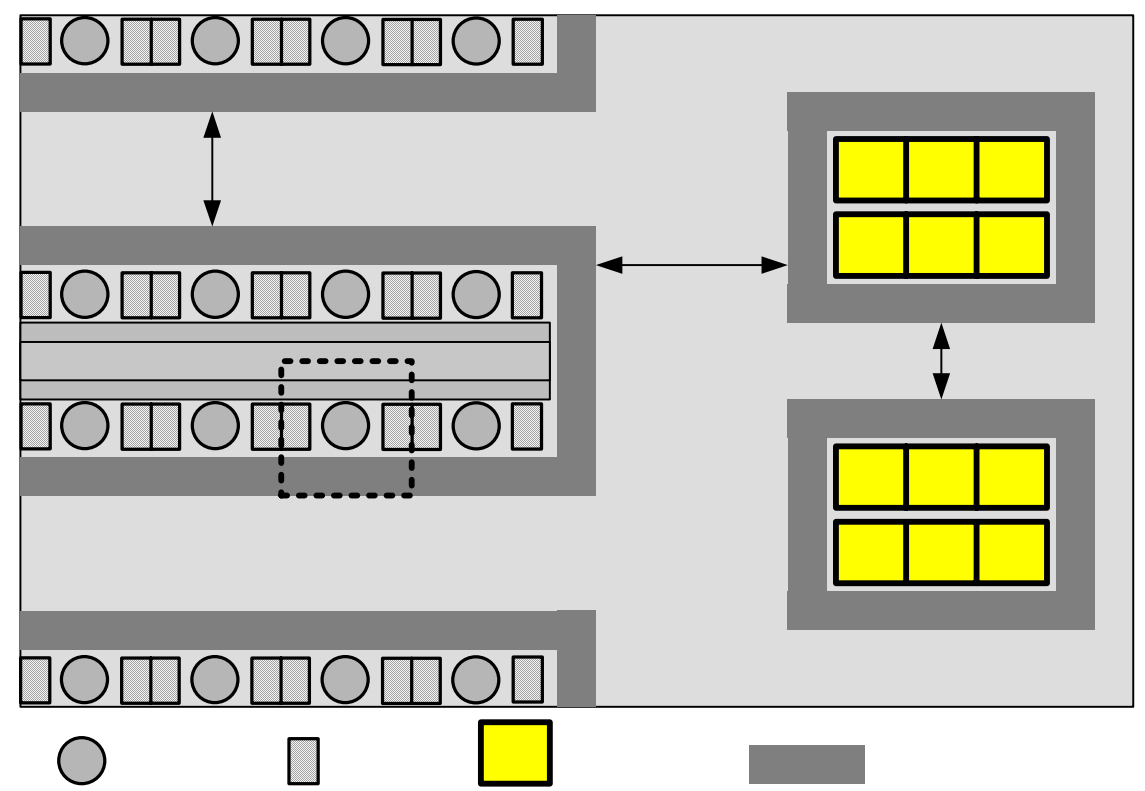

Fig. 8. Top view of general environment of manufacturing factory (dimensions in $[\mathrm{cm}]$ ). 


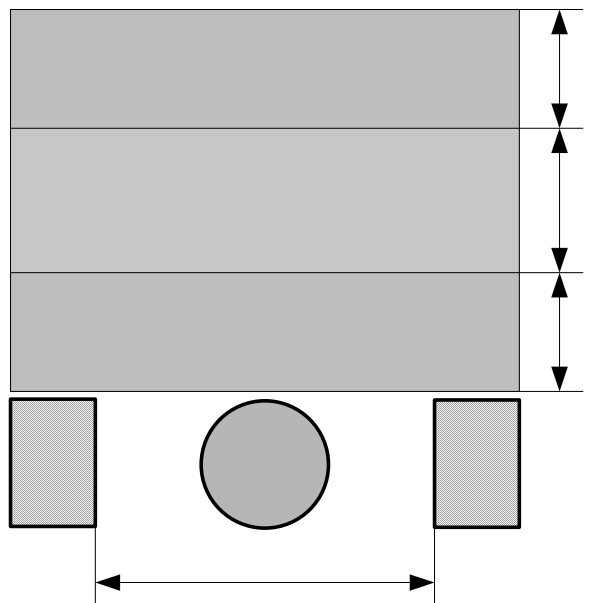

Fig. 9. Top view of space allocated for an employee working at worktable in manufacturing factories (dimensions in [cm]).

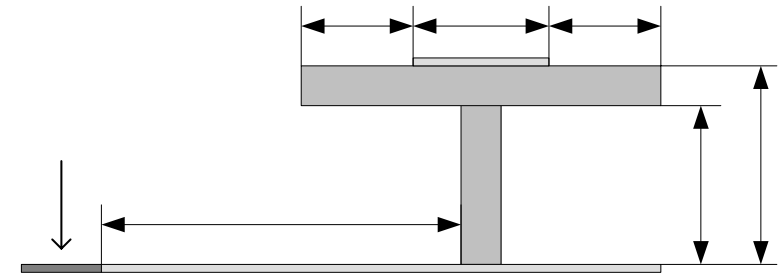

Fig. 10. Side view of space allocated for an employee working at worktable in manufacturing factories (dimensions in [cm]).

The major work in the factories is making electronic products such as battery chargers, vacuum cleaners and circuits that require soldering, and assembling task. For the tasks, as described in Fig. 8, most manufacturing factories are composed of long tables equipped with a conveyor, a warehouse containing parts in boxes on palettes, safety lines around these elements, and aisles between tables and storage areas. There are aisles with various widths, excluding the safety line width $(10 \mathrm{~cm})$ :

-between tables: $\min .120 \mathrm{~cm}$, max. $140 \mathrm{~cm}$

-between storage areas: $\min .80 \mathrm{~cm}, \max .120 \mathrm{~cm}$

-between tables and storage areas: $210 \mathrm{~cm}$

Allocated space for a worker who works at a worktable is expressed in the dotted box in Fig. 8 while Fig. 9 and Fig. 10 show top and side views of the space, respectively. For each worker doing table tasks, boxes containing parts are stacked at the left and right sides, and the width between the boxes is $75 \mathrm{~cm}$ at the minimum and $90 \mathrm{~cm}$ at the maximum. The table height of the lower side is $70 \mathrm{~cm}$ and the width between the safety line and table is about $100 \mathrm{~cm}$.

In the environment, workers perform dexterous tasks such as soldering and assembling at the work table. When workers do not have enough parts, they move to the warehouse, and pick up boxes that contain parts. After returning to the work table, they resume working. 


\subsection{Required Specification of Work Assistive Mobile Robot System}

The purpose of our robot system is to help the disabled to work in a factory environment. Therefore, the robot should have function on behalf of the legs and arms of the disabled worker. In a factory, workers carry boxes including assembled parts, load and unload boxes from a warehouse, and perform dexterous tasks. In order to help the disabled worker, we adopted a mobile platform with four wheels and equipped it with a forklift and a robot arm. The forklift helps to load and unload the boxes that contain parts to be assembled. Also, the robot arm helps to move light parts and to perform dexterous jobs such as providing aid when soldering.

From the environment survey results and task analysis, the required specifications for the mobile robot system are determined. The robot arm should be able to perform various dexterous tasks such as soldering, assembling, and moving light goods. The forklift should be able to lift up boxes that are more than $30 \mathrm{~kg}$. The mobile platform should be small enough to move through narrow aisles between tables in factories. The size of the robot system should be less than $1500 \mathrm{~mm}$ in length and $700 \mathrm{~mm}$ in width. The robot should be able to carry a payload of $120 \mathrm{~kg}$, including $80 \mathrm{~kg}$ for the worker's weight and $30 \sim 40 \mathrm{~kg}$ for a box.

By using this robot, the worker can easily move around, even in a confined area. The worker can also load, unload, and transfer boxes without difficulty. The robot arm also helps in performing dexterous tasks.

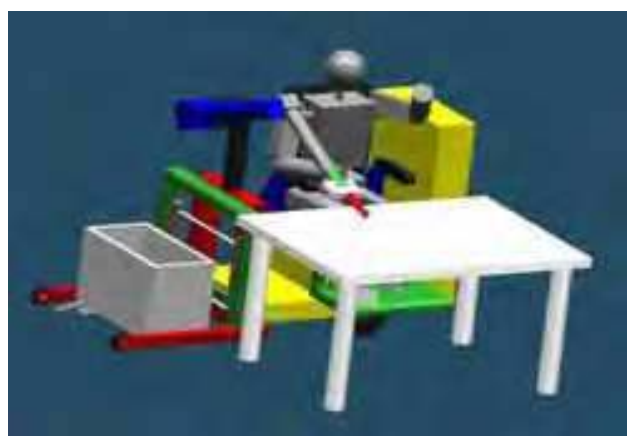

(a)

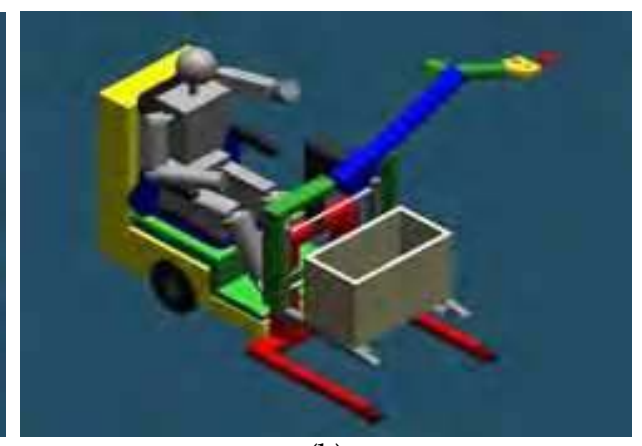

(b)

Fig. 11. Basic concept of work assistive mobile robot system type I; (a) assisting table tasks, (b) moving objects.

\section{Development of Work Assistive Robot Systems}

After a survey of general factories environments, we developed two work assistive robot systems. Work assistive mobile robot system type I is focused on versatility and work assistive robot system type II is mainly focused on mobility. Each robot system was developed after defining tasks and functions. We also conducted user-trials with the robot systems in a real factory to obtain feedback from real workers.

\subsection{Work Assistive Mobile Robot System Type I}

\subsubsection{Design of Work Assistive Mobile Robot System Type I}

We assume that the disabled user works sitting on the chair of the work assistive mobile robot. Therefore, the height of the robot chair should be designed to be lower than that of 
a desk. Furthermore, the chair should be designed to rotate up to a right angle to work at a desk. When parts to be assembled are needed or it is necessary to transfer goods, the person moves the robot and picks up and puts down the objects. Therefore, a fork-lift system is adopted in the robot system. When the robot moves, obstacle avoidance is employed and a related alarm is used for safety. The basic concept of the work assistive mobile robot system is described in Fig. 11. Fig. 11 describes a scenario to help the disabled person to work at their table tasks (soldering, assembling, etc.) and to move boxes containing parts. To support table tasks, the mobile robot is parked parallel with the table, and the chair of the robot is rotated toward the table. This setting makes it easy to use the robot arm to perform a task, and the fork-lift can be employed to load the box at the proper height.

The driving mechanism for the work assistive mobile robot is an important issue because the fork-lift must move heavy boxes. We considered two driving mechanisms: forward wheel steering/backward wheel driving and forward wheel driving/backward wheel steering. A forward wheel steering/backward wheel driving mechanism is a popular mechanism for three or four wheel scooters. However, this mechanism is not appropriate for a work assistive robot that has a fork-lift at its front area, especially with regard to steering. A forward wheel driving/backward wheel steering mechanism is also a popular mechanism for commercial forklift trucks, and is more appropriate. Therefore, we adopted a forward wheel driving/backward wheel steering mechanism.

\subsubsection{Development of Work Assistive Mobile Robot Type I}

Based on the design result of the robot, we developed work assistive mobile robot type I, as shown in Fig. 12. As noted earlier, the work assistive mobile robot type I is based on a forward wheel driving/backward wheel steering mechanism. For this mechanism, the robot has two motors, one for driving and another for steering. The mobile platform is basically controlled by a DSP controller and several peripherals. It also has four limit switches for emergency stopping, and ten ultrasonic sensors to detect obstacles to the rear for collision avoidance. Additionally, a camera is set up in the rear area and a monitor connected with it displays rear objects. The fork-lift system has two actuators to place and lift objects. A MANUS arm is equipped in front of the mobile platform. All components are controlled and communicated through the main system, which is run by a personal computer. Each component of work assistive mobile robot type I such as the robot arm, mobile platform, and fork lift is controlled by a 2-axis joystick, with several operation modes for controlling each component.

\begin{tabular}{|c|c|}
\hline Size & $650 \times 1400 \times 550[\mathrm{~mm}]($ width $\times$ length $\times$ height $)$ \\
\hline Speed & $12[\mathrm{~km} / \mathrm{h}]$ \\
\hline Max. Load (Robot) & $200 \mathrm{~kg}$ \\
\hline Max. Load (Lift) & $60 \mathrm{~kg}$ \\
\hline
\end{tabular}

Table 3. Specifications of work assistive mobile robot type I

From a structural point of view, we divided the work assistive mobile robot system into one main system and three subsystems according to their functions. Fig. 13 shows each module configuration of the robot system. 


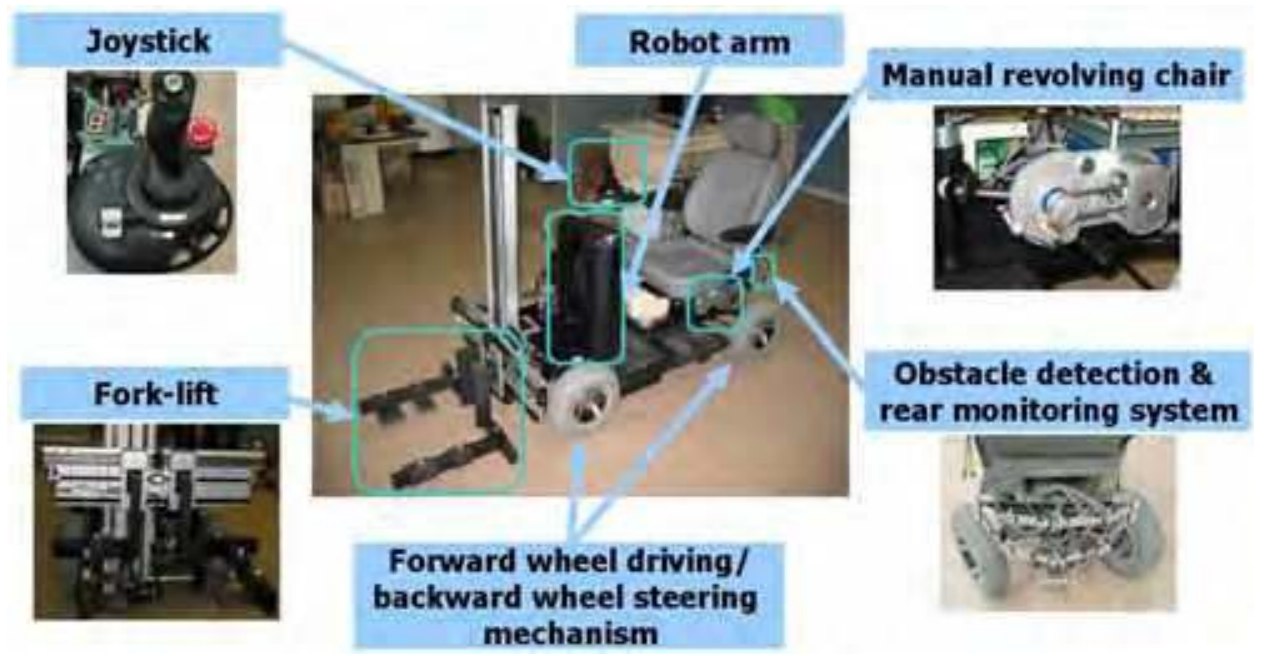

Fig. 12. Developed work assistive mobile robot type I.

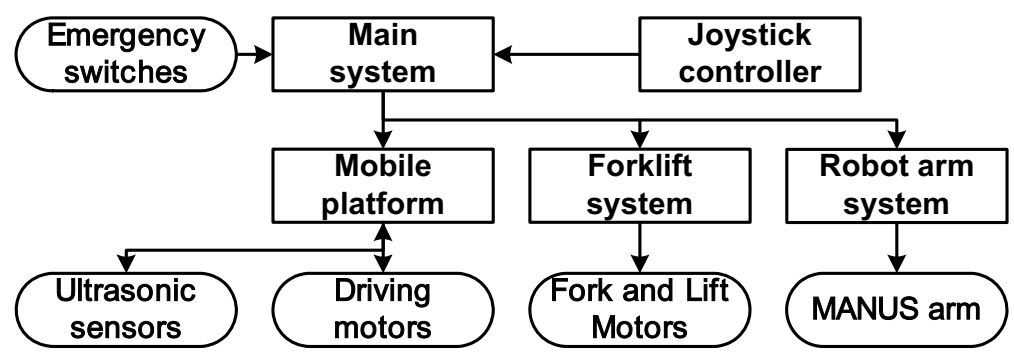

Fig. 13. Architecture of work assistive mobile robot type I.

The main system is a PC that runs RTAI-linux for real-time control. It is connected to subsystems, i.e., the mobile platform, fork-lift system, robot arm system, and the joystick controller. The joystick connection uses a USB communication port of the main computer, whereas others connections are through the RS232 port. Command data is composed of a start byte, data bytes, and an end byte. The number of data bytes corresponds with the number of actuators in each subsystem. For example, a command data from the main system to the mobile platform has one start byte (eight bits), two data bytes, and one end byte. Each data byte has a value between -125 and 125 . The start byte value is 126 , and the value of the end byte is 127 . This short data length speeds up communication.

\subsubsection{User-trials}

We conducted a series of user-trials of the developed work assistive mobile robot system with the participation of disabled persons who work in actual manufacturing factories, Boram-Dongsan and Mugungwha Electronics in Korea. We gathered their feedback about the robot. The participants were randomly selected among factory workers who have lowerlimb or upper-limb impairments or lower-limb and upper-limb impairments. Fig. 14 shows pictures describing the user-trials of work assistive mobile robot system type I. 
After conducting the user-trials of work assistive mobile robot system type I, we asked the subjects questions pertaining to the velocities of driving and steering, the convenience of the joystick interface, ease of riding, the risk during driving, and the need for the rear camera. The velocities of moving forward and reversing were confirmed by the respondents as being appropriate. However, they pointed out that the steering speed was slightly slow. This problem was caused by a high reduction ratio gearbox to generate high torque, and was fixed by using a gearbox with a lower gear ratio and a motor with higher torque. The respondents also said the joystick interface was very easy to use. They also reported that they felt safe while moving. This is due to the intuitive joystick control method and the ultrasonic sensor system to avoid collision with obstacles. However, they habitually did not use the rear monitoring system.

Additionally, we identified some shortcomings: (1) the robot arm system is hard to control, and should be smaller or be installed on a work desk; (2) the mobile base and the radius of turning of the robot need to be smaller and the chair needs to be rotated electrically and its should be height lower; and (3) the fork of the fork-lift system should smaller or capable of being folded electrically. We considered these problems for developing the next version, type II.

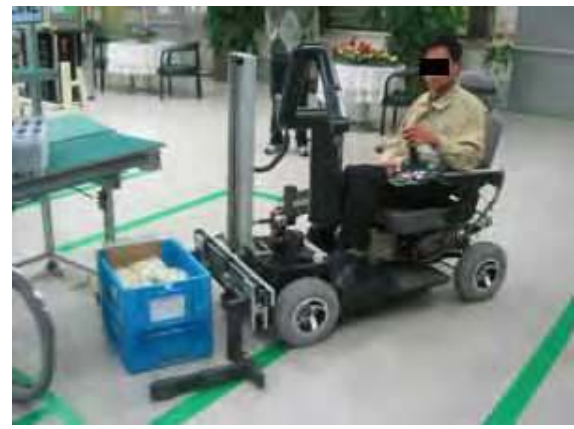

(a)

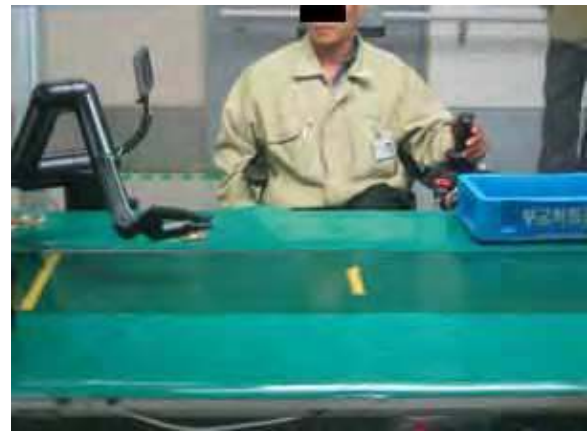

(c)

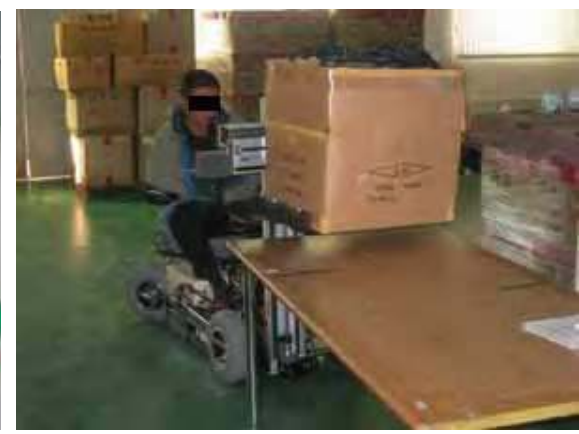

(b)

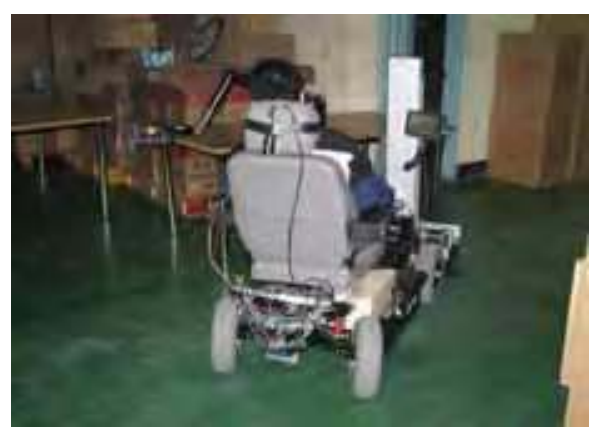

(d)

Fig. 14. User trials for Work Assistive Mobile Robot System Type I; (a) Moving objects lifting up, (b) Moving objects - lowering, (c) Working at a desk, (d) Moving around.

\subsection{Work Assistive Mobile Robot System Type II}

Based on the results of the user-trials of work assistive mobile robot system type I, we developed work assistive mobile robot system type II. The basic function, control system architecture, and the method of user-trials are basically the same as those of type I. 


\subsubsection{Design of Work Assistive Mobile Robot System Type II}

Since a robot arm is chiefly used in table tasks and is not used when the robot moves around, the robot arm is installed on the table, and a foldable fork-lift is incorporated in order to reduce the size of the robot. One very important issue is the driving mechanism. The robot should be capable of moving in a confined space. For this, we adopted an omni-directional wheel driving mechanism. Among the available omni-directional wheels, we use four omni-directional wheels called 'mecanum wheels'. A mecanum wheel consists of one active main wheel and several passive rollers around the main wheel. When the main wheel rotates, a force vector along the wheel and a force vector perpendicular to the wheel are created. The net force, which determines the moving direction of the robot, is created by combining each force vector of the four wheels. By simply controlling the rotation of each wheel without steering them, the robot can move in any direction. Although the power efficiency of the omni-directional mechanism is relatively low and it is difficult to fabricate mecanum wheels, we choose this mechanism since the use of four wheels will guarantee stability. By using the omni-directional wheel driving mechanism, positioning tasks become much easier, especially in narrow aisles, for upper limb impaired workers.
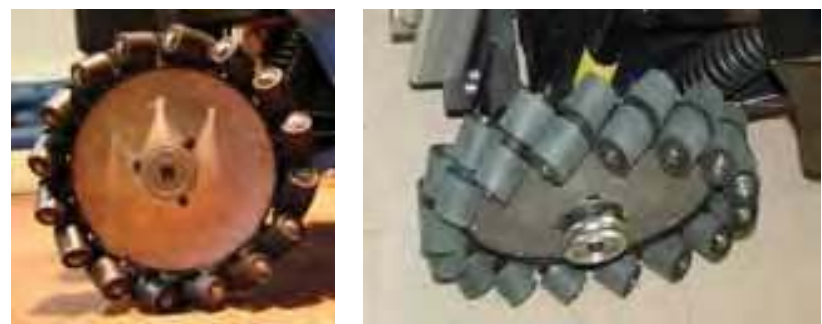

Fig. 15. Mecanum wheel for omni-directional movement.

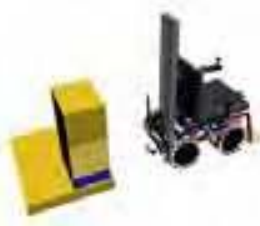

(a)

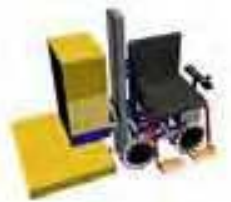

(e)

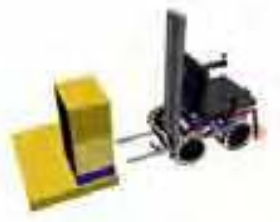

(b)

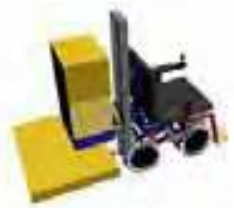

(f)

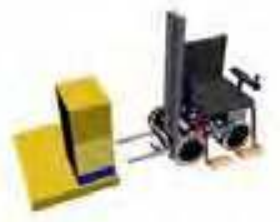

(c)

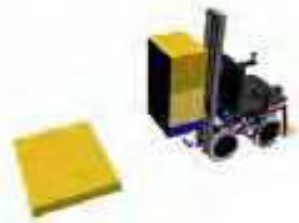

(g)

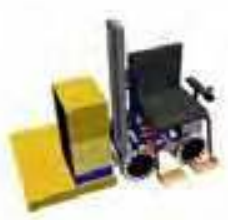

(d)

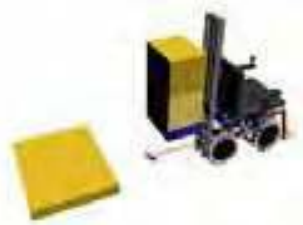

(h)

Fig. 16. Scenario of work assistive mobile robot type II; (a) robot moves to the warehouse and orients the rear side to a box on a pallet in the warehouse; (b) the user unfolds the fork using switch; (c) the user rotates the chair using a switch and prepares to extract the box; (d) the robot moves toward the box, and grips the pallet; (e) the user makes the robot raise the fork using a switch; (f) the user rotates the chair using the switch toward forward; (g) the robot moves toward the table; (h) when moving boxes, two sonar sensors are stretched out by DC motors so as not to interfere with boxes on the fork-lift. 
Fig. 16 describes the task of moving a box from a warehouse to a work table. When the user simply moves around, the fork is folded, and thus the actual size of the robot is relatively small. When the user picks up boxes, he/she unfolds the fork. While lifting objects, the user can vary the rotation angle to see and check the objects of interest by revolving the chair electrically.

During the transfer of objects, the robot can be used in a confined environment since its steering radius is actually zero. When the user works at a table, the chair can be rotated toward the table.

\subsubsection{Development of Work Assistive Mobile Robot System Type II}

Fig. 17 shows the developed work assistive mobile robot type II. As noted earlier, for in order to realize a robot with a smaller size and smaller turning radius, we used an omnidirectional driving mechanism at the cost of efficiency and excluded the robot arm subsystem. We adopted a foldable fork controlled by motors and equipped the fork-lift system at the rear side. We also adopted an electrically revolving chair so that the user can face the forklift when operating it. Two sonar sensors are used to detect obstacles in the rear. All these components are controlled by a 3-axis joystick and several switches and buttons.

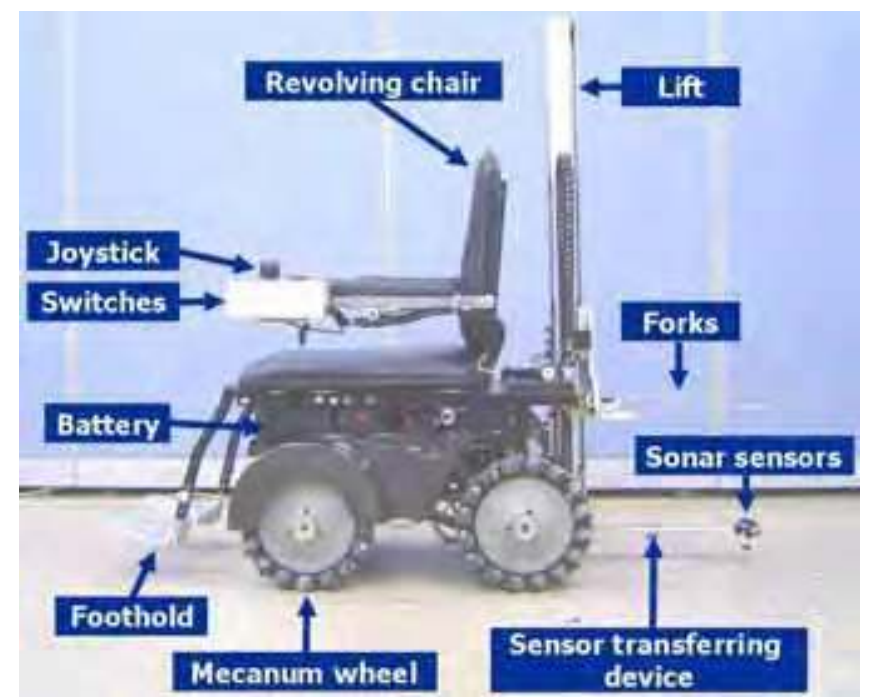

Fig. 17. Developed work assistive mobile robot type II.

\begin{tabular}{|c|c|c|c|}
\hline Size & \multicolumn{3}{|c|}{$760 \times 1140 \times 510[\mathrm{~mm}](\mathrm{W} \times \mathrm{LxH})$} \\
\hline \multirow[t]{3}{*}{ Speed(Robot) } & \multirow[t]{2}{*}{ Translation } & Slow Mode & $2.5 \sim 3[\mathrm{~km} / \mathrm{h}]$ \\
\hline & & Fast Mode & $5[\mathrm{~km} / \mathrm{h}]$ \\
\hline & Rotation & \multicolumn{2}{|c|}{$45[\mathrm{deg} / \mathrm{s}]$} \\
\hline Speed(Chair) & Rotation & \multicolumn{2}{|c|}{$18.4[\mathrm{deg} / \mathrm{s}]$} \\
\hline Max. Load(Robot) & \multicolumn{3}{|c|}{$120 \mathrm{~kg}$} \\
\hline Max. Load(Lift) & \multicolumn{3}{|c|}{$35 \mathrm{~kg}$} \\
\hline
\end{tabular}

Table 4. Specifications of work assistive mobile robot type II. 

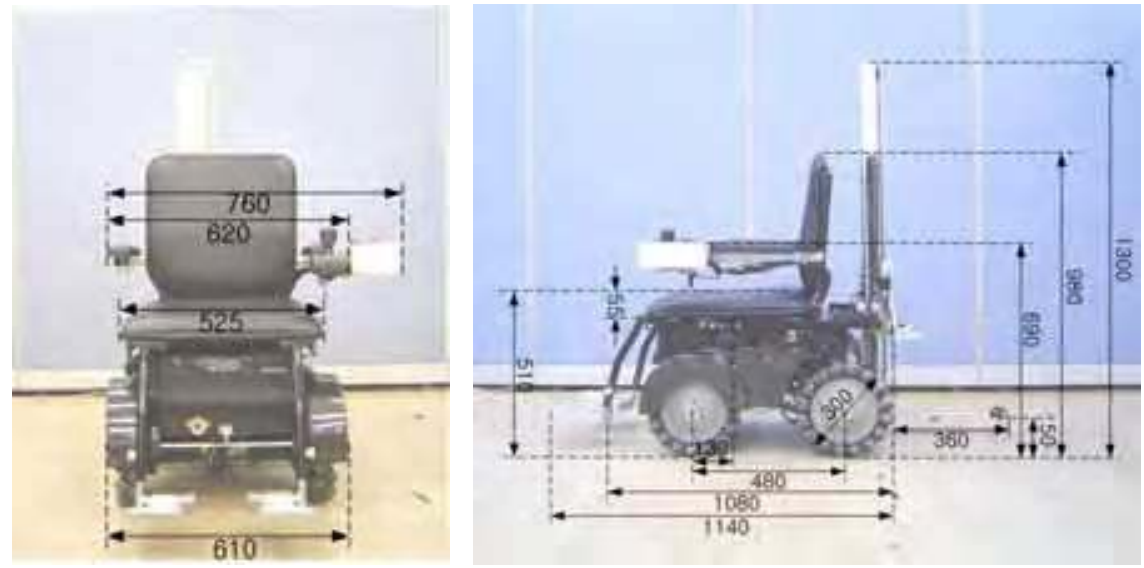

Fig. 18. Developed work assistive mobile robot type II (dimensions in [mm]).

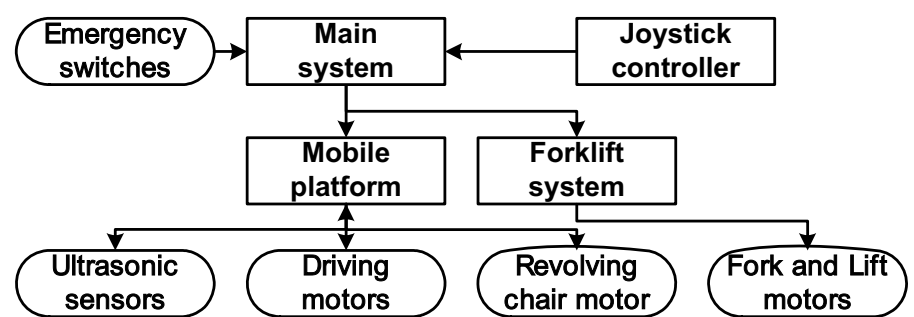

Fig. 19. Architecture of work assistive mobile robot type II.

Fig. 18 shows the developed work assistive mobile robot type II along with its size. The developed robot is small enough to assist in the performance of table tasks. Furthermore, the robot can be parked parallel with the table, and the chair can be rotated to face the table. In addition, the fork is foldable, and the fork-lift can be used as a box feeding device.

The work assistive mobile robot system type II consists of one main system and two subsystems, a mobile platform and a fork lift system. Fig. 19 shows each module configuration. The main system, which is based on FPGA (Field Programmable Gate Array) circuit, receives user input from the joystick controller and emergency switches. According to the user input, the main system gives commands to the mobile platform components such as four driving motors, the revolving chair motor, ultrasonic sensors, and the fork lift system components.

\subsubsection{User-trials}

Among the enhancements of the work assistive mobile robot system type II, many users applauded the omni-directional mechanism because of its ease of control. Fig. 20 shows pictures of the user-trials.

The participants commented that, "it is very good idea to move boxes when moving around", "the robot is small enough, having a similar size to an electrical wheelchair", "due to the small size, table work is possible without transferring to the table chair", "due to the omnidirectional wheel driving mechanism and joystick, it is very easy to control the mobile robot", and "the collision avoidance device helps avoid collisions". However, some participants said, 
"to avoid collisions in the rear, a rear monitoring system may be needed". This is because the work assistive mobile robot type II does not adopt a rear monitoring system.

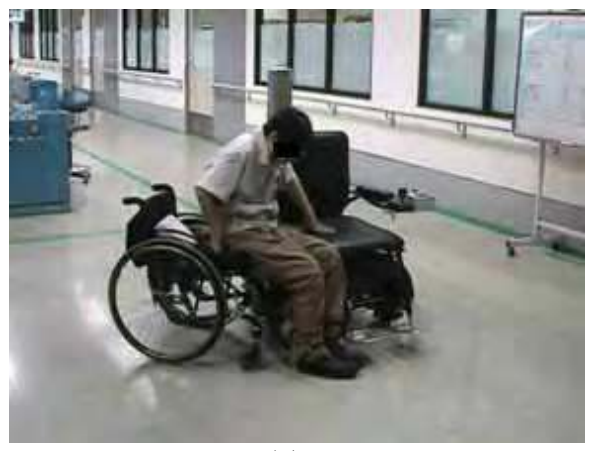

(a)

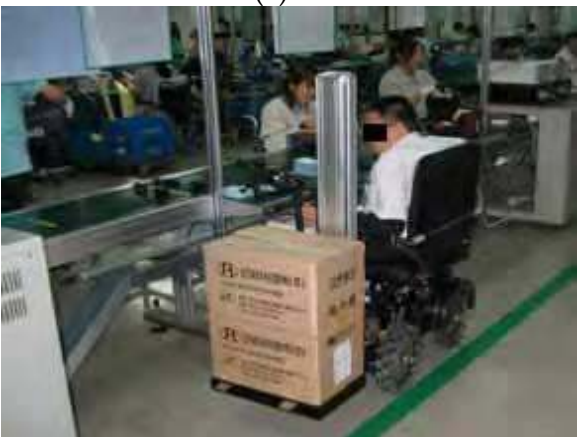

(c)

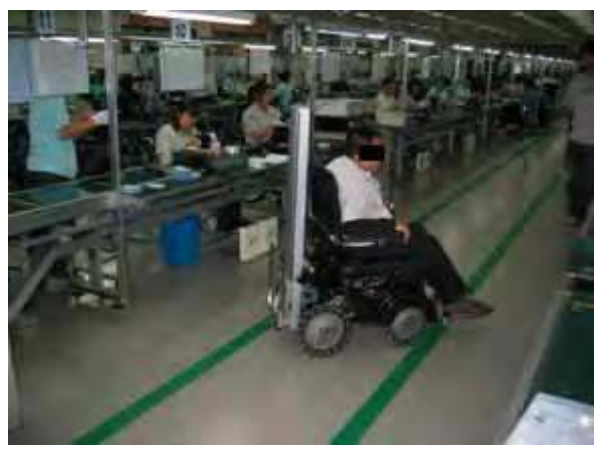

(b)

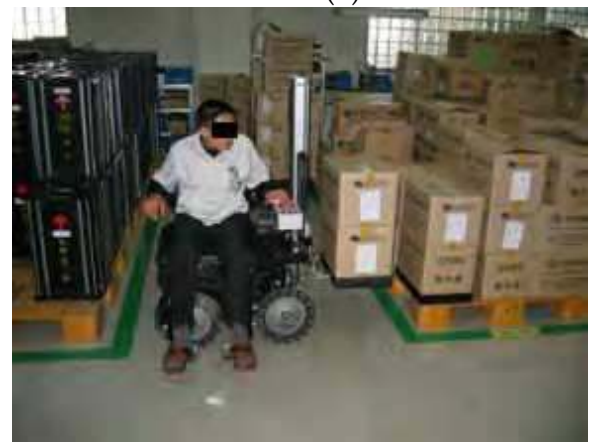

(d)

Fig. 20. User trials for Work Assistive Mobile Robot System Type II; (a) Transferring boxes, (b) Moving around, (c) Working at a desk, (d) Moving boxes.

\section{Conclusion}

Considering the real employment situation of the disabled, it was concluded that there is demand for a robot system that can be used in a real manufacturing environment. To derive our mission statement, we conducted a survey with three criteria: 'A. to assist the disabled as much as possible'; 'B. to consider the real situation of employment for the disabled'; and 'C. to provide assistance for the most necessary tasks for the disabled in the work space'. Based on the survey results, our goal can be stated as follows: To develop work assistive mobile robots to help persons with limb disabilities obtain jobs in manufacturing environments where they can perform simple manual labor. Here, simple labor includes such tasks as circuit inspection and moving boxes.

For our goal, we developed two types of work assistive mobile robots, which are small enough to work in the confined environments of real factories. Work assistive mobile robot type I is equipped with a forklift to move boxes and a robotic arm to help with jobs requiring more dexterity. Robot type II is compact in size, adopting an omni-wheel driving mechanism, and is equipped with a lift having a foldable fork. We gathered feedback from empirical work done on the two robots. 
It has been verified by user-trials and feedback that the proposed work assistive robot is capable of assisting a person with a disability to work in a manufacturing environment and perform the same tasks as a normally-abled worker. Further study should be carried out to make the proposed robot more convenient to operate and smaller in size.

\section{Acknowledgment}

This work was supported by the SRC/ERC program of MOST/KOSEF (grant \#R11- 1999-008).

\section{References}

Bien, Z.; Kim, D. J.; Chung, M. J.; Kwon, D. S. \& Chang, P. H. (2003). Development of a wheelchair-based rehab robotic system(KARES II) with various human-robot interaction interfaces for the disabled, Proceedings of the 2003 IEEE/ASME International Conference on Advanced Intelligent Mechatronics (AIM2003), ISBN 0-78037759-1, Kobe, Japan, Jul. 2003.

Chang, P. H.; Park , S. R.; Cho, G. R.; Jung, J. H. \& Park, S. H. (2005). Development of a robot arm assisting people with disabilities at working place using task-oriented design, Proceedings of the 9th International Conference on Rehabilitation Robotics (ICORR 2005), pp. 482-487, ISBN 0-7803-9004-0, Chicago, IL, USA, Jun. 28 - Jul 1, 2005.

Eftring, H. \& Bolmsjö, G. (1993). RAID - A robotic workstation for the disabled, Proceedings of the 2nd European Conference on the Advancement of Rehabilitation Technology, pp 24.3, ISBN 91-88336-19-0, Stockholm, Sweden, May 1993.

Hong, H. S.; Jung, S. Y.; Jung, J. H.; Lee, B. G.; Kang, J. W.; Park, D. J. \& Chung, M. J. (2005). Development of work assistive mobile robot system for the handicapped in a real manufacturing environment, Proceedings of the 9th International Conference on Rehabilitation Robotics (ICORR 2005), pp. 197-200, ISBN 0-7803-9004-0, Chicago, IL, USA, Jun. 28 - Jul 1, 2005.

Kim, Y.; Park, K. H.; Bang, W. C.; Kim, M. J.; Han, J. S. \& Bien, Z. (2002). Development of intelligent bed-robot system for the elderly or the disabled, Proceedings of $3 \mathrm{rd}$ International Workshop on Human-friendly Welfare Robotic Systems(HWRS 2002), pp. 94-98, Daejeon, Korea, Jan. 20-22, 2002.

Martens, C.; Ruchel, N.; Lang, O.; Ivlev, O. \& Graser, A. (2001). A FRIEND for assisting handicapped people, Robotics $\mathcal{E}$ Automation Magazine, Vol. 8, issue 1, Mar. 2001, pp. 57-65, ISSN 1070-9932.

Neveryd, H. \& Bolmsjö, G. (1994). WALKY, a mobile robot system for the disabled, Proceedings of the Fourth International Conference on Rehabilitation Robotics (ICORR 1994), pp. 137-141, Wilmington, Delaware, USA, Jun. 1994.

Van der Loos, H. F. M.; Wagner, J. J.; Smaby, N.; Chang, K.; Madrigal, O.; Leifer, L. J. \& Khatib, O. (1999). ProVAR assistive robot system architecture, Proceedings of the 1999 IEEE International Conference on Robotics and Automation (ICRA 1999), Detroit, pp. 741-746, ISBN 0-7803-5180-0, Michigan, USA, May 1999.

Yoo, D. H.; Hong, H. S.; Kwon, H. J. \& Chung, M. J. (2003). Human-friendly care robot system for the elderly, Proceedings of the 8th International Conference on Rehabilitation Robotics (ICORR 2003), pp. 188-191, ISBN 89-88366-09-3, Daejeon, Korea, Apr. 2003.

Yoo, D. H. \& Chung, M. J. (2003). Non-contact eye gaze estimation system using robust feature extraction and mapping of corneal reflections, Proceedings of International Conference of Advanced Robotics (ICAR 2003), pp. 911-913, ISBN 972-96889-8-2, Coimbra, Portugal, Jun. 2003. 


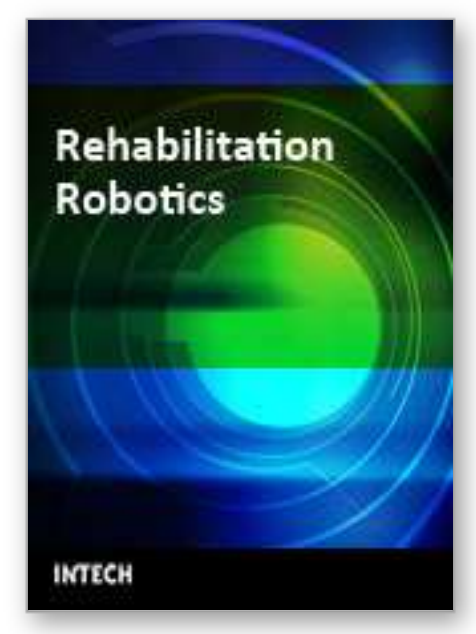

\author{
Rehabilitation Robotics \\ Edited by Sashi S Kommu
}

ISBN 978-3-902613-04-2

Hard cover, 648 pages

Publisher I-Tech Education and Publishing

Published online 01, August, 2007

Published in print edition August, 2007

The coupling of several areas of the medical field with recent advances in robotic systems has seen a paradigm shift in our approach to selected sectors of medical care, especially over the last decade.

Rehabilitation medicine is one such area. The development of advanced robotic systems has ushered with it an exponential number of trials and experiments aimed at optimising restoration of quality of life to those who are physically debilitated. Despite these developments, there remains a paucity in the presentation of these advances in the form of a comprehensive tool. This book was written to present the most recent advances in rehabilitation robotics known to date from the perspective of some of the leading experts in the field and presents an interesting array of developments put into 33 comprehensive chapters. The chapters are presented in a way that the reader will get a seamless impression of the current concepts of optimal modes of both experimental and ap- plicable roles of robotic devices.

\title{
How to reference
}

In order to correctly reference this scholarly work, feel free to copy and paste the following:

Hyun Seok Hong, Jung Won Kang and Myung Jin Chung (2007). Work Assistive Mobile Robot for the Disabled in a Real Work Environment, Rehabilitation Robotics, Sashi S Kommu (Ed.), ISBN: 978-3-902613-04-2, InTech, Available from:

http://www.intechopen.com/books/rehabilitation_robotics/work_assistive_mobile_robot_for_the_disabled_in_a_ real_work_environment

\section{INTECH}

open science | open minds

\section{InTech Europe}

University Campus STeP Ri

Slavka Krautzeka 83/A

51000 Rijeka, Croatia

Phone: +385 (51) 770447

Fax: +385 (51) 686166

www.intechopen.com

\section{InTech China}

Unit 405, Office Block, Hotel Equatorial Shanghai

No.65, Yan An Road (West), Shanghai, 200040, China 中国上海市延安西路65号上海国际贵都大饭店办公楼 405 单元

Phone: +86-21-62489820

Fax: $+86-21-62489821$ 
(C) 2007 The Author(s). Licensee IntechOpen. This chapter is distributed under the terms of the Creative Commons Attribution-NonCommercial-ShareAlike-3.0 License, which permits use, distribution and reproduction for non-commercial purposes, provided the original is properly cited and derivative works building on this content are distributed under the same license. 